\title{
Sistem Pemungutan Suara Elektronik Menggunakan Model Poll Site E-Voting
}

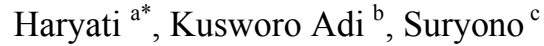 \\ ${ }^{a}$ STMIK WIT Cirebon Jawa Barat \\ b c Jurusan Fisika,Fakultas Sains dan Matematika Universitas Diponegoro \\ Naskah Diterima : 14 Januari 2014; Diterima Publikasi : 17 Maret 2014
}

\begin{abstract}
Pemilihan umum (Pemilu) merupakan agenda rutin bagi negara demokrasi, pemungutan suara berbasis kertas yang selama ini diterapkan, memiliki beberapa kelemahan, diantaranya surat suara rusak, ketidaktelitian dalampenghitungan suara dan pengumuman hasil pemilu yang cenderung lama. Oleh karena itu perludibuat sebuah sistem pemungutan suara secara elektronik yang user friendly terhadap masyarakat Indonesia. Dengan tetap mendatangi tempat pemungutan suara, akan memperhalus kekagetan perubahan dari sistem sebelumnya. Pemungutan suara secara elektronik bertujuan untuk meningkatkan partisipasi, akurasi hasil dan efisiensi pemilu. Pemungutan suara secara elektronikmempunyai tantangan tersendiri pada penerapannya di Indonesia, mulai dari belum adanya payung hukum, heterogennya tingkat pendidikan, kultur budaya masyarakat dan kesenjangan digital. Model yang dikembangkan pada tesis ini adalah poll site e-voting, berbasis aturan (rule based) Komisi Pemilihan Umum (KPU) sebagai penyelenggara Pemilu. Pada model ini, masyarakat tetap mendatangi tempat pemungutan suara, menggunakan Nomor Induk KTP sebagai alat verifikasidan memberikan suaranya pada bilik suara yang disediakan. Sistem secara otomatis menyimpan hasil pilihan pada database, dan setelah waktu yang ditentukan akan menampikan hasil dari pemungutan suara dan informasi lainnya yang dibutuhkan oleh KPU. Sistem pemungutan suara dengan model poll site e-votingini diharapkan mempunyai peluang yang baik dan tingkat resiko yang rendah untuk diterapkan di Indonesia.
\end{abstract}

Kata kunci : E-voting; Poll site; Rules based; Risk

\section{Abstrak}

General elections is a regular agenda for a democtaric state, the applied paper based voting has several drawbacks, including spoiled ballots, inaccuracy in the counting of votes and reporting of election results which tends to be slow. Therefore , it needs to develop an electronic voting system that is user friendly for Indonesian people, which will reduce confusion from the previous system changes. Electronic voting aims at increasing participation, accuracy and efficiency of election results. Electrinoc voting has its own challenges to the implementation in Indonesia, ranging from the lack of legal protection, the heterogeneous level of education, culture, soceity and the digital gaps. The model developed in this thesis is the poll site evoting, based on the rules of General Elections Commision (KPU) as the organizer of the elections. In this model, people still go to the pools, using the ID number od ID card as a verification tool and voting at the voting booths provided. The system automatically stores the results in a database option, and after the spesified time will show both the results of the voting and other and other information required by the Commission. Voting system with a model of e-voting poll site is expected to have a good chance an a low level of risk to be applied in Indonesia.

Keywords : E-voting; Poll site; Rule based; Risk.

\section{Pendahuluan}

Pemilihan umum (pemilu) merupakan bagian penting dari proses demokrasi untuk menentukan suatu keputusan yang dapat diterima oleh semua orang (Cedo et al., 2012). Dalam demokrasi, setiap individu memiliki kebebasan untuk mengekspresikan dirinya melalui pemilihan umum, sesuai dengan aturan hukum yang berlaku (Dwumfuo dan Paatey, 2011). Pemungutan suara (voting) yang merupakan bagian penting dari pemilu adalah sebuah metode dimana beberapa atau sekelompok orang melakukan

*) Penulis korespondensi: arieaja@yahoo.com suatu keputusan, baik itu keputusan politik, sosial maupun publik (Dwumfuo dan Paatey, 2011).

Pemungutan suara berbasis kertas yang selama ini telah berjalan, memiliki beberapa kelemahan, di antaranya ketidaktelitian dalam penghitungan suara dan pengumuman hasil pemilu yang tertunda (Qadah dan Taha, 2007). Selain itu, membutuhkan biaya operasional dan logistik yang besar, proses perhitungan memerlukan waktu lama, dan prosedur rentan terhadap kesalahan manusia, terutama pada pemungutan suara yang kompleks (Cedo et al., 2012). Waktu yang lama dalam proses perhitungan juga dapat menjadi celah kecurangan. Isu-isu seputar 
pemungutan suara telah memunculkan pemikiran tentang membangun sistem pemungutan suara yang lebih modern, yaitu e-voting. E-voting merupakan sistem pemberian suara pada pemilihan umum yang menggunakan komputer atau peralatan terkomputerisasi (Cetinkaya dan Cetinkaya, 2007). E-voting bertujuan meningkatkan partisipasi, menurunkan biaya pemilu dan meningkatkan akurasi hasil (Qadah dan Taha, 2007). Sistem e-voting memungkinkan terselenggaranya pemilu yang lebih sederhana dan mengurangi total biaya pemilu secara signifikan (Dwumfuo dan Paatey, 2011). Melalui sistem e-voting, penggunaan kertas dapat ditekan sesedikit mungkin. Sistem e-voting dapat dilihat sebagai "proses bisnis" dari rangkaian proses pemilihan umum, dan diharapkan dapat menekan penggunaan kertas dalam pemungutan suara.

Penelitian e-voting sejauh ini tentang mengoptimalkan penggunaan solusi teknologi dengan aplikasi ICT (Information and Comunication Technology). Beberapa negara sudah melakukan pengujian penggunaan e-voting dengan model dan teknologi yang berbeda-beda, seperti menggunakan punch-cards, pemindaian optik (untuk memindai surat suara) dan sistem Direct Recording Electronik (Cedo et al., 2012). Sistem pemungutan suara dapat juga diklasifikasikan berdasarkan lokasi (Cedo et al., 2012), yaitu poll site based systems dan remote voting systems. Poll site based systems merupakan cara pemungutan suara dimana pemilih menuju tempat pemungutan suara yang telah disediakan oleh penyelenggara pemilu, sedangkan remote voting systems memungkinkan pemilih dapat memilih dari mana saja. Beberapa sistem yang dapat diklasifikasikan ke dalam remote voting systems diantaranya: vote-by-mail, internet voting, e-mail voting, sms voting dan supervise remote.

Pada beberapa wacana, e-voting memiliki tantangan tersendiri dalam penerapannya di Indonesia, kebiasaaan masyarakat yang cenderung enggan mempelajari cara-cara baru sampai heterogen nya tingkat pendidikan yang berdampak pada kesenjangan pemahaman penggunaan alat digital. $E$ voting merupakan kajian multi disiplin ilmu yang melihat pemungutan suara dari beberapa sudut pandang, dari sisi rekayasa perangkat lunak, kriptografi, politik, hukum, ekonomi dan sosial (Cetinkaya dan Cetinkaya, 2007).

Pada penelitian ini, akan dibangun sebuah sistem $e$-voting berbasis web dengan sistem online di tempat pemungutan suara (TPS), atau disebut poll-site $e$ voting. Aturan yang diintegrasikan pada sistem poll site e-voting ini mengacu pada peraturan Komisi Pemilihan Umum (KPU), diantaranya peraturan KPU tentang pedoman tata cara pelaksanaan pemungutan dan penghitungan suara pemilihan umum kepala daerah dan wakil kepala daerah di tempat pemungutan suara (TPS). Pada model yang dikembangkan ini, pemilih tetap mengunjungi tempat pemungutan suara (TPS) yang disediakan oleh penyelenggara pemilu. Sistem lebih ditekankan pada kemudahan penggunaan dari sisi user/pemilih, yang diharapkan dapat memperbaiki kelemahan dari sistem sebelumnya.

E-voting memiliki persyaratan umum agar hasilnya tidak keluar dari kerangka pemungutan suara. Persyaratan umum yang menjadi parameter bagi sistem e-voting, ditunjukkan pada Tabel 1 . (Cetinkaya dan Cetinkaya, 2007).

Tabel 1. Persyaratan umum e-voting (Cetinkaya dan Cetinkaya, 2007).

\begin{tabular}{ll}
\hline Privacy & $\begin{array}{l}\text { Tidak ada yang tau pilihan apa yang } \\
\text { dipilih oleh pemilih }\end{array}$ \\
\hline Eligibility & $\begin{array}{l}\text { Hanya pemilih yang memenuhi } \\
\text { persyaratan saja yang berhak untuk } \\
\text { memilih. }\end{array}$ \\
\hline Uniqueness & $\begin{array}{l}\text { Setiap pemilih hanya berhak memilih } \\
\text { satu kali. }\end{array}$ \\
\hline Uncoercibility & $\begin{array}{l}\text { Pemilih harus memilih secara bebas, } \\
\text { tidak dibawah tekanan siapapun. }\end{array}$ \\
\hline Receipt- & $\begin{array}{l}\text { Pemilih tidak memberitahuan pada } \\
\text { freeness }\end{array}$ \\
& $\begin{array}{l}\text { siapapun apa pilihannya pada } \\
\text { mencegah jual beli suara. }\end{array}$ \\
\hline Fairness & $\begin{array}{l}\text { Tidak ada penghitungan parsial } \\
\text { sebelum akhir periode voting untuk } \\
\text { memastikan bahwa semua kandidat } \\
\text { diberi keputusan yang adil. }\end{array}$ \\
\hline Transparency & $\begin{array}{l}\text { Proses voting keseluruhan harus } \\
\text { transparan. Papan buletin, atau layar } \\
\text { dapat untuk } \\
\text { mempublikasikan proses pemilu. }\end{array}$ \\
\hline Keakuratan hasil pemungutan suara, \\
suara yang telah masuk tidak dapat \\
diubah.
\end{tabular}

Gambaran umum proses e-voting dan aktor yang terlibat di dalamnya dapat di deskripsikan seperti pada gambar 1. (Cetinkaya dan Cetinkaya, 2007).

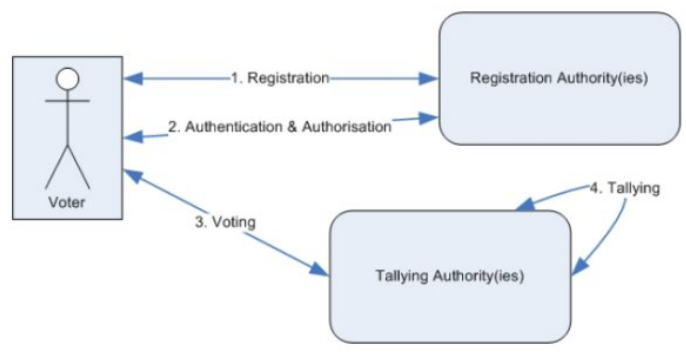

Gambar 1. Gambaran umum proses e-voting (Cetinkaya dan Cetinkaya, 2007)

\section{Kerangka Teori}

\subsection{Sistem Berbasis Aturan}


Rule based system atau sistem berbasis aturan menggunakan pernyataan IF-THEN, di mana di bagian THEN akan bernilai benar jika satu atau lebih sekumpulan fakta atau hubungan antar fakta diketahui benar, memenuhi bagian IF (Hartati dan Iswanti, 2008). Konsekuensi atau konklusi yang dinyatakan pada bagian THEN baru dinyatakan benar, jika bagian IF pada sistem tersebut juga benar atau sesuai dengan aturan tertentu (Krishnamoorthy dan Rajeev, 1996). Gambar 2 memperlihatkan konsep dasar mengenai sistem berbasis aturan (Sasikumar et al., 2011).

ruleid: If antecedent 1 and antecedent 2 .... then consequent

Gambar 2. Konsep dasar sistem berbasis aturan (Sasikumar M. et al., 2007)

Antecedent merupakan bagian yang mengekspresikan situasi atau premis, sedangkan consequent merupakan bagian yang menyatakan suatu konklusi atau tindakan yang diterapkan jika suatu premis bernilai benar. Untuk premis yang lebih dari satu, dapat dihubungkan dengan operator and atau or, sedangkan konklusi dapat berupa kalimat tunggal, beberapa kalimat yang dihubungkan dengan and, dan dimungkinkan dengan else. Gambar 3. menunjukkan komponen dari sistem berbasis aturan.

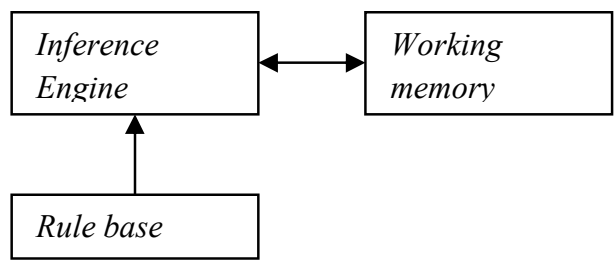

Gambar 3. Komponen dari sistem berbasis aturan (Sasikumar et al., 2007)

Rule base (disebut juga sebagai basis pengetahuan) merupakan sebentuk aturan yang dibangun untuk mengarahkan penggunaan pengetahuan dalam memecahkan masalah. Inference engine atau mesin inferensi mencoba memperoleh informasi baru mengenai masalah tertentu menggunakan aturan yang ada dalam basis pengetahuan. Sutojo et al., (2011) memaparkan mesin inferensi sebagai kumpulan prosedur atau program pemandu proses penalaran terhadap suatu kondisi berdasarkan basis pengetahuan yang ada untuk mencapai solusi. Working memory merupakan media penyimpanan atau basis data yang berisi kumpulan fakta yang hendak ditelusuri hubungannya.

Sistem berbasis aturan pada model poll site $e$ voting berkaitan dengan proses verifikasi pemilih, yang akan memeriksa berdasarkan fakta melalui identitas nomor induk KTP pemilih, apakah pemilih tersebut terdaftar pada daftar pemilih tetap atau tidak, sudah pernah memilih atau belum memilih, untuk menentukan apakah termasuk pemilih yang memenuhi syarat (eligible voter) atau tidak.

\subsection{Analisis Kebutuhan Sistem Poll Site e-voting}

Pada tahap ini dapat dirumuskan kebutuhan fungsional dan non fungsional sebagai berikut:

a. Kebutuhan Fungsional

1) Verifikasi pemilih

Sistem harus dapat melakukan verifikasi terhadap pemilih berdasarkan daftar pemilih tetap (DPT), sehingga dapat ditentukan apakah pemilih tersebut dapat melakukan pilihan atau tidak.

2) Pemungutan suara (Voting)

Hanya pemilih yang sudah teregistrasi pada proses verifikasi, yang dapat melakukan pemungutan suara, pemilih hanya bisa memilih satu kali. Identitas pemilih tidak dihubungkan dengan informasi mengenai hasil pilihannya, hal ini menjadi bagian dari kerahasiaan.

3) Perhitungan suara (Counting)

Setelah proses pemungutan suara selesai, sistem dapat melakukan perhitungan suara.

4) Laporan Hasil Perhitungan Suara

Hasil perhitungan suara dapat dilihat oleh semua orang sesaat setelah pemungutan suara selesai. Laporan hasil perhitungan suara tampil dalam bentuk grafik perolehan suara, grafik partisipasi masyarakat dan sertifikat hasil.

\section{b. Kebutuhan Non Fungsional}

1) Kemudahan sistem

Sistem dirancang agar mudah digunakan oleh pemilih. Dengan desain surat suara yang mirip seperti surat suara berbasis kertas, tanpa harus menggulung layar atau mengklik OK berkali kali, diharapkan akan memperhalus perubahan mekanisme dari sistem sebelumnya.

2) Kinerja

Agar sistem dapat berjalan dengan baik, harus didukung dengan perangkat keras dan perangkat jaringan yang memadai, baik dari sisi client maupun dari sisi server.

3) Keamanan data hasil pemungutan suara

Data hasil pemungutan suara di encrypt menggunakan sistem enkripsi yang aman, saat ini sudah banyak model enkripsi yang dapat digunakan bagi sistem berbasis web, salah satunya adalah metode AES.

4) Keamanan jaringan

Dari sisi teknologi, penyampaian hasil pemungutan suara dari client di tiap-tiap TPS sampai ke server di KPU harus melalui jalur yang aman, Penggunaan VPN (Virtual Private Network) menjadi salah satu pilihan, karena dapat digunakan untuk database terpusat yang mengkomunikasi kan hubungan client-server melalui internet. Pertimbangan kerjasama antara KPU dengan dinas terkait bisa menjadi salah satu strategi bagi aspek keamanan jaringan. 


\subsection{Skema poll site e-voting}

Sistem dibagi menjadi dua sudut pandang, yaitu KPU dan TPS, yang diimplementasikan menjadi empat modul sesuai dengan petugas yang mengakses sistem, yaitu KPPS 1, KPPS 2, Ketua KPPS, dan Admin KPU. Admin KPU bertugas mengelola data master dan melakukan aktifasi e-voting. Informasi yang dapat diakses oleh Admin KPU adalah rekap perolehan suara, sertifikat $e$-voting dan partisipasi masyarakat. Petugas KPPS 1 bertugas melakukan verifikasi pemilih dan dapat melakukan pencarian bagi pemilih. Informasi yang dapat diakses oleh petugas KPPS 1 adalah grafik hasil perhitungan suara dan sertifikat hasil pemungutan dan perhitungan suara dari TPS tersebut. Petugas KPPS 2 bertugas melakukan pemanggilan pemilih berdasarkan nomor antrian ke bilik suara. Informasi yang dapat diakses oleh petugas KPPS 2 adalah history data pemilih, bukan hasil pilihannya. Modul surat suara akan muncul otomatis pada saat pemilih masuk ke bilik suara. Gambar 4. menunjukkan skema poll site evoting.

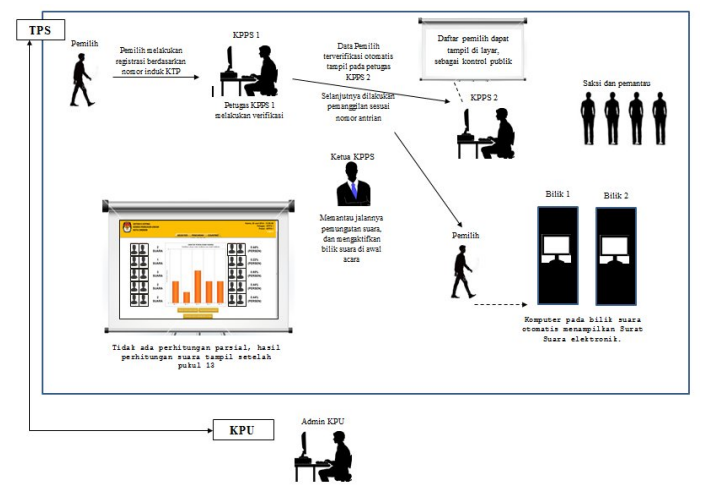

Gambar 4. Skema poll site e-voting

Pada prosedur verifikasi pemilih, diterapkan aturan-aturan yang menjadi dasar bagi penentuan apakah pemilih eligible untuk dapat memilih atau tidak. Tabel 2 menunjukkan aturan verifikasi pemilih.

Tabel 2. Aturan verifikasi pemilih pada sistem poll site e-voting

\begin{tabular}{cl}
\hline No & \multicolumn{1}{c}{ Aturan } \\
\hline R1 & $\begin{array}{l}\text { IF pemilih terdaftar di DPT } \\
\text { THEN syarat sebagai pemilih terpenuhi }\end{array}$ \\
\hline R2 & $\begin{array}{l}\text { IF pemilih belum memilih } \\
\text { THEN hak suara belum terpakai }\end{array}$ \\
\hline R3 & $\begin{array}{l}\text { IF waktu }>=\text { pukul 07.00 } \\
\text { AND waktu <= pukul 13.00 } \\
\text { THEN pemungutan suara masih berlangsung }\end{array}$ \\
& \multicolumn{1}{c}{ Aturan } \\
\hline No & $\begin{array}{l}\text { IF syarat sebagai pemilih terpenuhi AND hak suara } \\
\text { belum terpakai } \\
\text { THEN syarat administrasi untuk menggunakan hak pilih }\end{array}$
\end{tabular}

\begin{tabular}{|c|c|}
\hline & terpenuhi \\
\hline R5 & $\begin{array}{l}\text { IF syarat administrasi untuk menggunakan hak pilih } \\
\text { terpenuhi } \\
\text { AND proses pemungutan suara masih berlangsung } \\
\text { THEN Pemilih Bisa Memilih }\end{array}$ \\
\hline R6 & $\begin{array}{l}\text { IF pemilih tidak terdaftar di DPT } \\
\text { THEN syarat sebagai pemilih tidak terpenuhi }\end{array}$ \\
\hline R7 & $\begin{array}{l}\text { IF pemilih sudah memilih } \\
\text { THEN hak suara sudah terpakai }\end{array}$ \\
\hline R8 & $\begin{array}{l}\text { IF syarat sebagai pemilih tidak terpenuhi } \\
\text { OR hak suara sudah terpakai } \\
\text { THEN syarat administrasi untuk menggunakan hak pilih } \\
\text { TIDAK terpenuhi }\end{array}$ \\
\hline R9 & $\begin{array}{l}\text { IF waktu }>=\text { pukul } 13.00 \\
\text { THEN pemungutan suara sudah berakhir }\end{array}$ \\
\hline R10 & $\begin{array}{l}\text { IF syarat administrasi untuk menggunakan hak pilih } \\
\text { TIDAK terpenuhi } \\
\text { OR proses pemungutan suara sudah berakhir } \\
\text { THEN Tidak Bisa Memilih }\end{array}$ \\
\hline
\end{tabular}

\subsection{Permodelan sistem Poll Site E-Voting}

Permodelan sistem dirancang menggunakan UML. Gambar 5. menunjukkan Use case diagram dari sistem poll site e-voting.

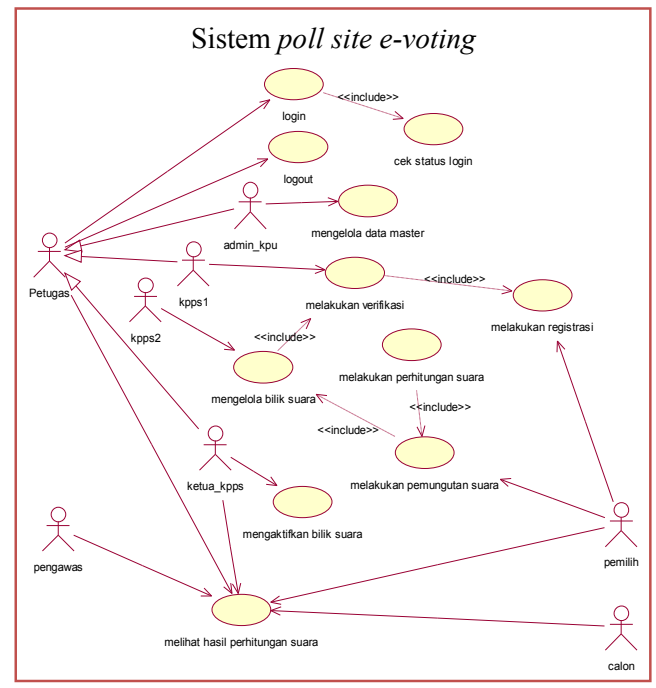

Gambar 5. Use case diagram sistem poll site e-voting

\section{Hasil dan Pembahasan}

Penelitian ini menghasilkan sebuah sistem pemungutan suara elektronik menggunakan model Poll Site E-Voting pada pemilihan umum di Indonesia, dengan studi kasus pemilihan kepala daerah, menggunakan sistem berbasis aturan pada prosedur verifikasi pemilih. Aturan yang menjadi acuan adalah peraturan KPU mengenai tata cara pemungutan dan perhitungan suara.

a. Form Login. Form login digunakan untuk petugas, yaitu Admin KPU, Ketua KPPS, KPPS 1 dan KPPS 2. Pemilih tidak memasukkan user id dan password, ini merupakan salah satu sisi kemudahan dari sisi pemilih. Gambar 6. menampilkan Form Login. 


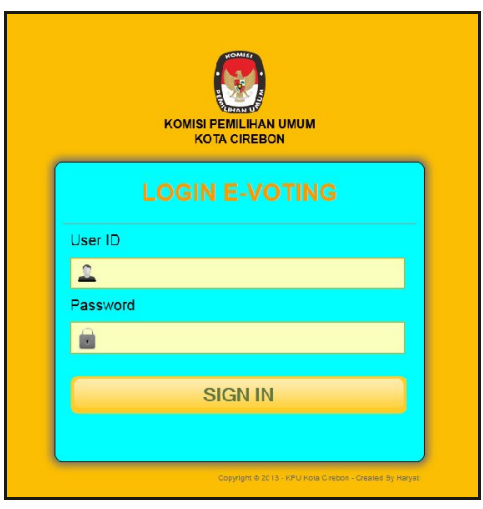

Gambar 6. Form Login

b. Form KPPS 1. Pemilih melakukan registrasi dengan menunjukkan nomor induk KTP, petugas KPPS1 melakukan verifikasi pada Form KPPS 1 yang menampilkan data DPT. Pada saat verifikasi, sistem akan memeriksa apakah pemilih terdaftar di DPT dan belum memilih, sebagai syarat administrasi untuk menggunakan hak pilih. Gambar 7 menunjukkan tampilan form registrasi. Gambar 8 menunjukkan source code yang memeriksa data pemilih terhadap DPT.

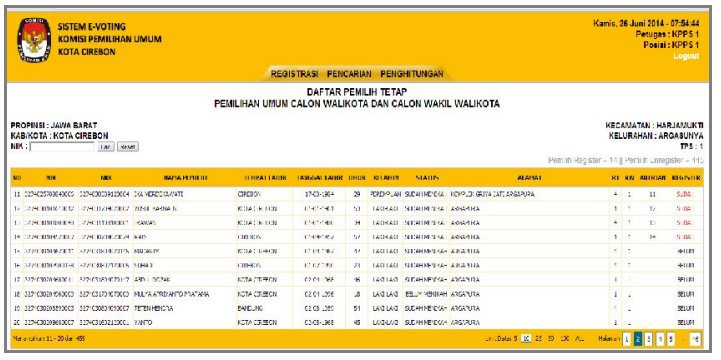

Gambar 7. form KPPS 1 menu registrasi

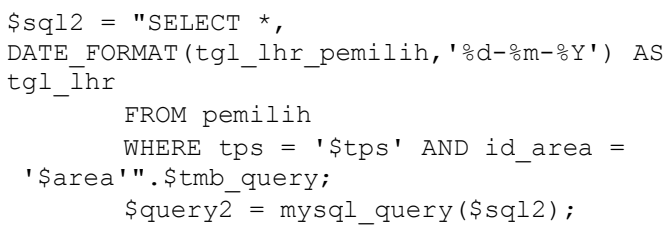

Gambar 8. Source code memeriksa data pemilih terhadap DPT

Gambar 9. menunjukkan Popup menu yang akan muncul sebagai tindakan verifikasi. Selain syarat administrasi, sistem juga menentukan apakah proses pemungutan suara masih berlangsung atau sudah memasuki waktu perhitungan suara.

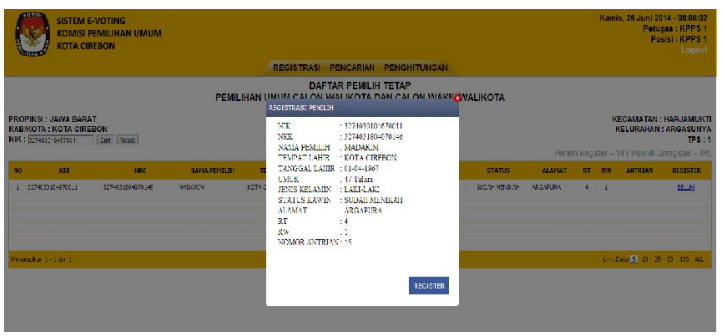

Gambar 9. Popup menu registrasi pemilih

Source code periksa status pemilih dapat dilihat pada gambar 10 Source code waktu tutup voting diperlihatkan pada gambar 11 .

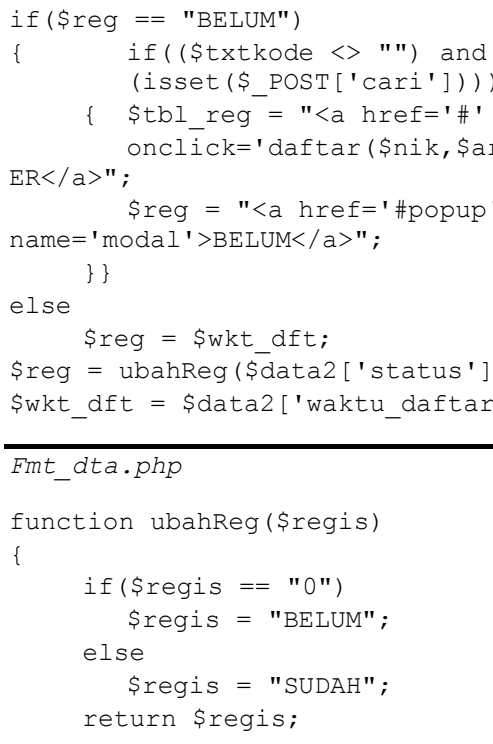

Gambar 10. Source code periksa status pemilih

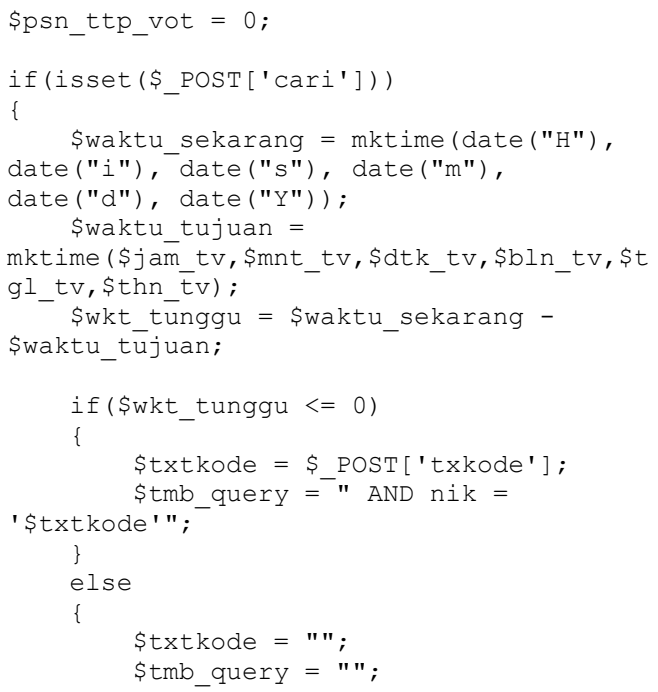

Gambar 11. Source code memeriksa tanggal dan waktu tutup voting 
Menu pencarian pada Form KPPS 1 digunakan apabila nama pemilih tidak ada pada daftar TPS, melalui menu ini dapat diketahui pada TPS berapa seharusnya pemilih tersebut memilih. Menu Perhitungan aktif setelah pukul 13, sesaat setelah pemungutan suara selesai. Pada menu Perhitungan, dapat dilihat grafik perolehan suara, partisipasi masyarakat serta sertifikat hasil dan rincian e-voting pada TPS tersebut. Gambar 12 menunjukkan menu perhitungan sebelum pukul 13.

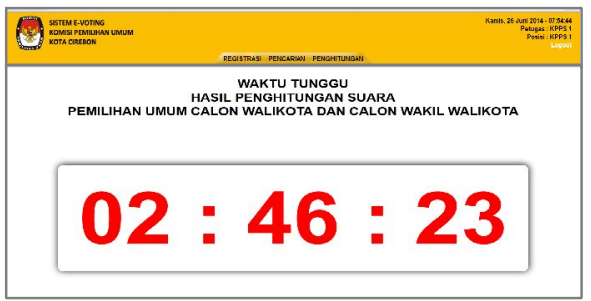

Gambar 12. Form KPPS 1 menu perhitungan

c. Form KPPS 2. Form E-Voting otomatis menampilkan daftar nama pemilih yang telah terverifikasi oleh KPPS 1. Panel kanan menampilkan nomor antrian dan nama pemilih yang akan dipanggil, jika pemilih tidak ada saat dipanggil, maka petugas KPPS 2 akan mengklik tombol TUNDA, sehingga nomor antrian dan nama pemilih tersebut masuk dalam Daftar Pemilih Tunda, panel kanan akan berubah lagi untuk daftar pemilih berikutnya. Gambar 13 menunjukkan daftar pemilih tunda.

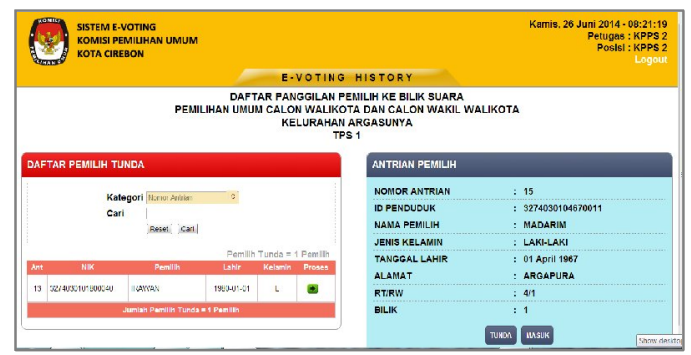

Gambar 13. Form KPPS 2 menu e-voting daftar pemilih tunda

Gambar 14 menunjukkan tampilan Surat Suara Elektronik, pemilih melakukan klik pada salah satu foto pasangan calon.

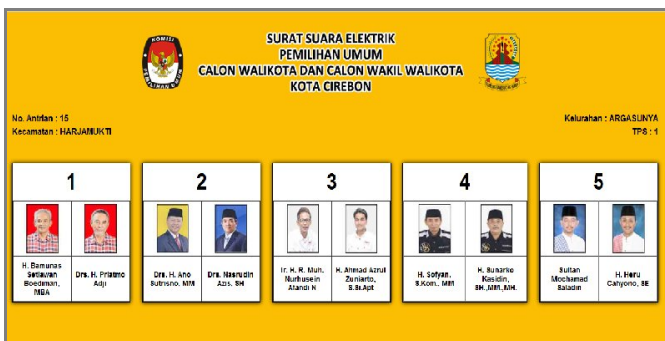

Gambar 14. Tampilan surat suara elektronik d. Form Admin KPU. Admin KPU bertanggung jawab mengimport data master ke dalam sistem. Data master yang dimaksud adalah Data DPT, Data Petugas KPPS, Data Calon dan Data TPS.

Mengadaptasi mekanisme sistem sebelumnya, dimana KPU perolehan data DPT dari petugas PPK di tingkat kecamatan, yang merupakan data update DPT yang sudah ditetapkan. Sistem dapat mengimport data berupa file Excel yang di peroleh dari petugas PPK, dan dapat menyaring data ganda di file yang diperoleh tersebut. Gambar 15 menunjukkan menu import data DPT.

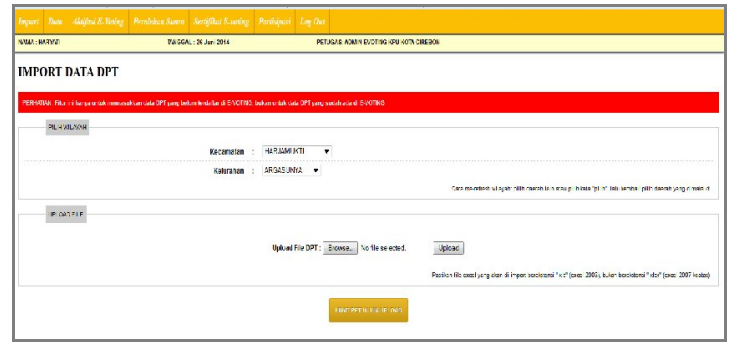

Gambar 15. Menu import data DPT

Admin KPU dapat melihat hasil perolehan suara dari tingkat TPS, Kelurahan, Kecamatan dan tingkat Kota. Gambar 16 menunjukkan perolehan suara dari setiap calon pada tingkat Kota.

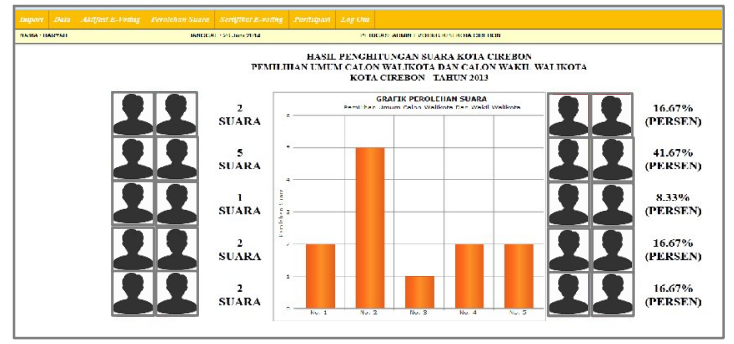

Gambar 16. Grafik hasil perhitungan suara tingkat kota

Menu sertifikat $e$-voting merupakan rincian perhitungan suara yang diperoleh masing-masing calon. Sertifikat hasil ini dapat dilihat dari tingkat TPS, Kelurahan, Kecamatan dan tingkat Kota. Gambar 17 menunjukkan menu sertifikat $e$-voting.

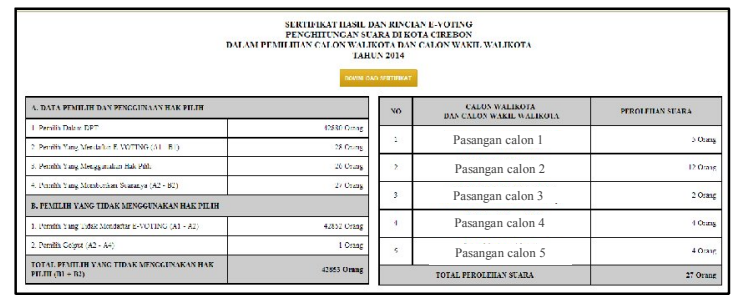

Gambar 17. Sertifikat hasil e-voting tingkat kota 
Menu partisipasi menampilkan informasi mengenai tingkat partisipasi masyarakat pada tingkat Kelurahan, Kecamatan dan Kota. Informasi ini memuat angka dan persentase dari pemilih yang menggunakan hak suaranya dan pemilih yang tidak menggunakan hak suaranya atau yang biasa disebut golput. Pemilih yang masuk pada bilik suara dan memilih pada salah satu pasangan calon, maka suaranya diikutsertakan kedalam kategori partisipasi masyarakat. Partisipasi masyarakat dihitung berdasarkan jumlah suara, bukan jumlah registrasi pemilih. Informasi partisipasi masyarakat ini digunakan sebagai tolak ukur keberhasilan pemilu. Gambar 18 menunjukkan grafik tingkat partisipasi masyarakat.

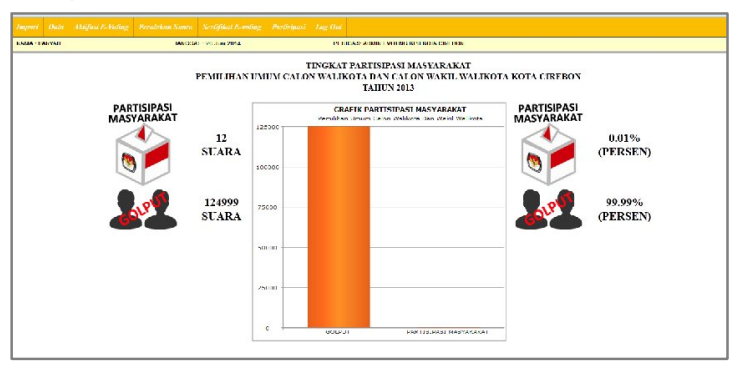

Gambar 18. Grafik tingkat partisipasi masyarakat

Pengujian terhadap kebutuhan fungsional dan non fungsional dari sistem, yang dilakukan secara black box testing terlihat pada tabel 3 .

Tabel 3. Pengujian sistem

\begin{tabular}{|c|c|c|c|}
\hline No & Pengujian & Target & $\begin{array}{l}\text { Hasil } \\
\text { Pengujian }\end{array}$ \\
\hline 1. & $\begin{array}{l}\text { Proses registrasi } \\
\text { pemilih } \\
\text { berdasarkan } \\
\text { nomor induk } \\
\text { KTP, petugas } \\
\text { KPPS1 } \\
\text { melakukan } \\
\text { verifikasi. }\end{array}$ & $\begin{array}{l}\text { Pemilih dengan } \\
\text { nomor induk KTP } \\
\text { yang ada dalam DPT } \\
\text { dan belum memilih, } \\
\text { dapat melakukan } \\
\text { registrasi. }\end{array}$ & $\begin{array}{l}\text { Sesuai } \\
\text { target }\end{array}$ \\
\hline 2. & $\begin{array}{l}\text { Pemilih dengan } \\
\text { no induk KTP } \\
\text { tidak terdaftar di } \\
\text { DPT }\end{array}$ & $\begin{array}{l}\text { Pemilih tidak dapat } \\
\text { memilih. }\end{array}$ & $\begin{array}{l}\text { Sesuai } \\
\text { target }\end{array}$ \\
\hline 3. & $\begin{array}{l}\text { Pemilih yang } \\
\text { sudah melakukan } \\
\text { pilihan } \\
\text { sebelumnya }\end{array}$ & $\begin{array}{l}\text { Pemilih tidak dapat } \\
\text { melakukan } \\
\text { pemilihan lagi. }\end{array}$ & $\begin{array}{l}\text { Sesuai } \\
\text { target }\end{array}$ \\
\hline 4. & $\begin{array}{l}\text { Tampilan menu } \\
\text { pada petugas } \\
\text { KPPS } 2\end{array}$ & $\begin{array}{l}\text { Daftar nama pemilih } \\
\text { yang sudah } \\
\text { melakukan registrasi } \\
\text { tampil secara } \\
\text { otomatis pada } \\
\text { petugas KPPS } 2\end{array}$ & $\begin{array}{l}\text { Sesuai } \\
\text { target }\end{array}$ \\
\hline 5. & $\begin{array}{l}\text { Pemilih } \\
\text { melakukan pilihan } \\
\text { di bilik suara }\end{array}$ & $\begin{array}{l}\text { Surat suara akan } \\
\text { tampil di bilik suara. } \\
\text { Informasi yang } \\
\text { terkait dengan surat } \\
\text { suara, dapat dilihat } \\
\text { dengan jelas. }\end{array}$ & $\begin{array}{l}\text { Sesuai } \\
\text { target }\end{array}$ \\
\hline
\end{tabular}

\begin{tabular}{|c|c|c|c|}
\hline No & Pengujian & Target & $\begin{array}{l}\text { Hasil } \\
\text { Pengujian }\end{array}$ \\
\hline 6. & $\begin{array}{l}\text { Pemilih tidak } \\
\text { memilih di bilik } \\
\text { suara selama } 3 \\
\text { menit. }\end{array}$ & $\begin{array}{l}\text { Setelah } 3 \text { menit, } \\
\text { surat suara akan } \\
\text { tertutup secara } \\
\text { otomatis dan pemilih } \\
\text { dianggap telah } \\
\text { menggunakan hak } \\
\text { pilihnya. Nilainya } \\
\text { akan dihitung } \\
\text { sebagai golput }\end{array}$ & $\begin{array}{l}\text { Sesuai } \\
\text { target }\end{array}$ \\
\hline 7. & $\begin{array}{l}\text { Waktu sudah } \\
\text { menunjukkan } \\
\text { pukul } 13 .\end{array}$ & $\begin{array}{l}\text { Proses pemungutan } \\
\text { suara selesai, hasil } \\
\text { perhitungan suara } \\
\text { sudah bisa dilihat. }\end{array}$ & $\begin{array}{l}\text { Sesuai } \\
\text { target }\end{array}$ \\
\hline 8. & $\begin{array}{l}\text { Hasil perolehan } \\
\text { suara per TPS }\end{array}$ & $\begin{array}{l}\text { Hasil per TPS dapat } \\
\text { dilihat dalam bentuk } \\
\text { grafik dan sertifikat } \\
\text { hasil. }\end{array}$ & $\begin{array}{l}\text { Sesuai } \\
\text { target }\end{array}$ \\
\hline 9. & $\begin{array}{l}\text { Hasil perolehan } \\
\text { suara tingkat } \\
\text { Kelurahan, } \\
\text { Kecamatan dan } \\
\text { Kota }\end{array}$ & $\begin{array}{l}\text { Hasil per kelurahan } \\
\text { dapat dilihat dalam } \\
\text { bentuk grafik dan } \\
\text { sertifikat hasil. }\end{array}$ & $\begin{array}{l}\text { Sesuai } \\
\text { target }\end{array}$ \\
\hline 10 & $\begin{array}{l}\text { Saat koneksi } \\
\text { terputus, pemilih } \\
\text { sedang dibilik } \\
\text { suara dan belum } \\
\text { melakukan } \\
\text { pemilihan }\end{array}$ & $\begin{array}{l}\text { Saat koneksi } \\
\text { tersambung kembali, } \\
\text { surat suara masih } \\
\text { dalam kondisi aktif, } \\
\text { dan pemilih tersebut } \\
\text { dapat melanjutkan } \\
\text { untuk memilih. }\end{array}$ & $\begin{array}{l}\text { Sesuai } \\
\text { target }\end{array}$ \\
\hline
\end{tabular}

Pengujian simulasi sistem pemungutan suara elektronik dengan model poll site e-voting ini menggunakan sistem client-server. Admin KPU bertindak sebagai server dan petugas KPPS sebagai client dengan dua bilik suara, antrian pemilih berdasarkan urutan kehadiran saat verifikasi. Simulasi menggunakan data DPT di wilayah Kotamadya Cirebon. Database mampu menampung data simulasi tanpa gangguan yang berarti, proses import data yang dilakukan oleh admin KPU dapat mendeteksi kesalahan format penulisan dan data pemilih ganda berdasarkan nomor induk KTP. Surat suara elektronik menampilkan informasi pasangan calon dengan jelas, hasil pilihan tidak terhubung dengan identitas pemilih. Sistem dapat menampilkan hasil pemungutan suara berupa grafik hasil perolehan suara, sertifikat hasil pemungutan suara dan grafik partisipasi masyarakat dari sudut pandang TPS maupun Admin KPU kota. Pemungutan suara elektronik dengan model poll site e-voting ini dapat memenuhi persyaratan umum e-voting seperti yang dijelaskan pada tabel 1 .

\section{Kesimpulan}

Sistem pemungutan suara dapat diimplementasikan dalam bentuk pemungutan suara elektronik (e-voting). Sistem poll site e-voting yang dikembangkan pada penelitian ini memiliki prosedur dan tampilan yang user friendly bagi pemilih dan bagi KPU sebagai penyelenggara pemilihan umum. Sistem dapat menampikan hasil dari pemungutan 
suara dan informasi lainnya yang dibutuhkan sesaat setelah proses pemungutan suara selesai. Sistem poll site e-voting ini diharapkan mempunyai peluang yang baik serta tingkat resiko yang rendah untuk diterapkan di Indonesia.

\section{Daftar Pustaka}

Bradbury, M.E., Schröder, L.B., 2011. The content of accounting standards: Principles versus rules, Elsevier, The British Accounting Review.

Cedo, R., Ahullo, J., Roca, J.C., Viejo, A., 2012. Study on poll-site voting and verification systems. Elsevier, Computers \& Security, 9891010.

Cetinkaya, O. and Cetinkaya, D., 2007. Verification and validation issues in electronic voting. The Electronic Journal of e-Government Volume 5 Issue 2, pp $117-126$.

Council of Europe, 2010. E-voting handbook, Directorate of Democratic Institutions, Directorate General of Democracy and Political Affairs, Strasbourg - France.

Dennis A., Wixom B.H., Tegarden D., 2005. Systems Analysis and Design with UML Version 2.0. John Wiley \& Sons, Inc., United States of America.

Dwumfuo, G.O. Ofori., Paatey, E., 2011. The design of an electronic voting systems. Research Journal of Information Technology3(2): 91-98.

Lai, J.Y., Lin, C.F., Yang, C.H., 2009. Design and Implementation of an Electronic Voting System with Contactless IC Cards.

Lee, G.H., 2008. Rule-based and case-based reasoning approach for internal audit of bank, Elsevier, knowledge based systems 21,140-147.

Liptrott M., 2007. E-voting: same pilots, same problems, different agendas. The Electronic Journal of e-Government Volume 5 Issue 2, pp $205-212$.
Musa, M.A., Aliyu, F.M., 2013. Design of electronic voting systems for reducing election process. International Journal of Recent Technology and Engineering (IJRTE).

Panduan KPPS Pemilukada, 2010. KPU.

Peraturan Komisi Pemilihan Umum nomor 15 tahun 2010, 2010. tentang perubahan atas peraturan komisi pemilihan umum nomor 72 tahun 2009 tentang pedoman tata cara pelaksanaan pemungutan dan penghitungan suara pemilihan umum kepala daerah dan wakil kepala daerah di tempat pemungutan suara.

Peraturan Komisi Pemilihan Umum nomor 16 tahun 2010, 2010. tentang pedoman tata cara pelaksanaan rekapitulasi hasil penghitungan perolehan suara dalam pemilihan umum kepala daerah dan wakil kepala daerah oleh panitia pemilihan kecamatan, komisi pemilihan umum kabupaten/kota, dan komisi pemilihan umum provinsi, serta penetapan calon terpilih, pengesahan pengangkatan, dan pelantikan

Pressman, R. S., 2001. Software Engineering: A Practitioner's Approach, McGraw-Hill.

Undang-Undang Republik Indonesia, Nomor 32 tahun 2004 tentang Pemerintahan Daerah.

Qadah, G.Z., Taha, R., 2007. Electronic voting systems: Requirements, design, and implementation, Elsevier, Computer Standards \& Interfaces, 376-386.

Weldemariam, K., Kemmerer, R., Villafiorita, A., 2011. Formal analysis of an electronic voting system: An experience report. The Journal of Systems and Software 84 1618-1637.

Zarei, S., Malayeri, A.D., Mastorakis, N.E., E-Voting and E-Democracy: basic approach to EGovernment issuance, ISBN:978-1-61804-084-8. 